\title{
ESCOLAS DE LUTA: \\ CENAS DA POLÍTICA E EDUCAÇÃO
}

OCCUPIED SCHOOLS:

POLITICAL AND EDUCATIONAL SCENES

\author{
ESCUELAS DE LUCHA: \\ POLITICA Y LA EDUCACION ESCENAS
}

Bruno Teixeira Paes ${ }^{1}$
Isaac Pipano $^{2}$

RESUMO

Esse ensaio busca explorar a experiência das ocupações nas escolas secundaristas de São Paulo por meio de algumas das imagens produzidas pelos estudantes. Seguindo uma estrutura próxima da dinâmica dos planos filmicos, nosso trabalho propõe uma articulação entre os discursos (visuais e narrativos) das ocupações compartilhadas nas redes sociais, por meio da análise das provocações que esses novos papéis desempenhados pelos secundaristas colocaram em relação à própria ideia de representação da escola, aluno e currículo. Ao pensarmos a prática educativa neste cenário de (re)organização provocado pela resposta do movimento dos secundaristas, remetemos tal experiência aos pensamentos de Jacques Rancière (2012) e César Migliorin (2008), quando estes refletem sobre os encontros no "sensível", oportunizados pelos diferentes espaços escolares. Em outro ponto, buscou-se o conceito de zona autônoma temporária apresentado por Hakim Bey (2004), para pensarmos este outro espaço em transformação de tempos, espaços, posturas, relações e corpos. Ao reconfigurar o espaço sensível das escolas, os estudantes vivenciam uma experiência (corpórea e intelectualmente) emancipatória, fazendo da escola como um espaço de invenção. Por fim, nosso ensaio destaca a dimensão da resistência política e dos conflitos, que foram registrados e divulgados pelos secundaristas em meio a um cenário no qual o currículo da educação básica se aproxima de um ideal quantitativo voltado para o espetáculo dos dados. O que os secundaristas nos interrogam é uma abertura para suas demandas, uma chamada por escutas dentro das políticas públicas voltadas para a educação.

PALAVRAS-CHAVE: Educação. Ocupações secundaristas. Políticas públicas. Narrativas audiovisuais. Manifestações sociais.

\section{ABSTRACT}

This essay seeks to explore the experience of occupations in secondary schools in São Paulo through some of the images produced by the students. Following a structure close to the dynamics of film plans, our work proposes an articulation between the discourses (visual and narrative) of the occupations shared in the social networks, through the analysis of the provocations that these new roles played by the secondary students put in relation to the very idea of representation of school, student and curriculum. When thinking about the educational practice in this scenario of (re) organization provoked by the response of the secondary school movement, we refer such experience to the thoughts of Jacques Rancière (2012) and César Migliorin (2008),

\footnotetext{
${ }^{1}$ Doutorando em Educação - Faculdade de Educação da Universidade Federal do Rio de Janeiro (FE-UFRJ); Professor substituto da Faculdade de Educação da Universidade Federal Fluminense (FEUFF). Rio de Janeiro, RJ. Email: bruno.paes@gmail.com

${ }^{2}$ Doutorando em Comunicação - Universidade Federal Fluminense (UFF). Rio de Janeiro, RJ. Email: isaacpipano@gmail.com Submetido em: 29/11/2016 Aceito em: 10/02/2017
}

(C) ETD-Educação Temática Digital Campinas, SP $\quad$ v.19 $\quad$ n.1 $\quad$ p. 3-25 jan./mar. 2017 
when they reflect on the "sensible" different of school spaces. In another point, we sought the concept of temporary autonomous zone presented by Hakim Bey (2004), to think about this other space in transformation of times, spaces, postures, relations and bodies. By reconfiguring the sensitive space of schools, students experience an emancipatory (bodily and intellectually) emancipatory, placing the school as a space for invention. Finally, our essay highlights the extent of political resistance and conflicts, which were recorded and disseminated by secondary school students in a setting in which the basic education curriculum approaches a quantitative ideal for the data show. What high school students question is an openness to their demands, a call for eavesdropping within public policies geared toward education.

KEYWORDS: Education. Secondary occupations. Public policy. Audiovisual narratives. Social manifestations.

\section{RESUMEN}

Este ensayo trata de explorar la experiencia de las ocupaciones de escuelas secundarias de São Paulo por medio de algunas de las imágenes producidas en ellas. Siguiendo una estructura dinámica semejante a las de las tomadas de la película, nuestro trabajo sugiere una relación entre los discursos de las ocupaciones (visuales y narrativos) compartidos en las redes sociales, a través del análisis de las provocaciones que estos nuevos papeles desempeñados por los estudiantes la escuela secundaria colocaron en relación la propia idea de representación de la escuela, de los estudiantes y del currículo. Al pensar en la práctica educativa en este escenario de (re) organización causado por el movimiento de la respuesta de la escuela secundaria, remitimos dicha experiencia a los pensamientos de Jaques Rancière (2012) y Cézar Migliorin (2008), cuando ellos reflexionan sobre los encuentros en lo "sensible" que son propiciados por los diferentes espacios de la escuela. En otro momento, se buscó el concepto de zona temporalmente autónoma presentada por Hakim Bey (2004), para que este otro espacio en el procesamiento de tiempos, espacios, actitudes, relaciones y cuerpos. Al reconfigurar el espacio sensible de las escuelas, los estudiantes experimentan una experiencia (física e intelectualmente) emancipatorio, poniendo a la escuela como un espacio de invención. Por último, nuestro artículo pone de relieve la dimensión de la resistencia y conflictos políticos, los cuales fueron registrados y liberada por la escuela secundaria en medio de un escenario en el que el plan de estudios de educación básica enfoques cuantitativos de ideales frente al espectáculo de datos. Lo que la escuela secundaria para interrogar es una apertura para sus demandas, una llamada con la exploración de las políticas públicas para la educación.

PALABRAS CLAVE: Educación. Ocupaciones de secundaria. Políticas públicas. Narrativas audiovisuales. Manifestaciones sociales.

\section{INTRODUÇÃO: E SE O DESEJO FOSSE À ESCOLA?}

CENA 1: No alto dos ombros de um rapaz cujo rosto não vemos, uma garota, não mais que 15 anos, rosto pintado como uma máscara de guerra, comanda uma multidão. Entre os corpos, estudantes, pais, jornalistas. Smartphones e tablets registram tudo em velocidade instantânea. A cada frase dita pela garota um coro entoa as mesmas palavras, sílaba a sílaba...gritos de ordem são repetidos: " - Enquanto não cair a reorganização, vamos seguir lutando enquanto esse decreto não for barrado! OCUPAR É RESISTIR! OCUPAR É RESISTIR!". A frase repercute entre os demais, entre saltos e tambores, palmas e gritos, contagiados pela luta. ${ }^{3}$.

\footnotetext{
${ }^{3}$ Todas as cenas aqui descritas foram retiradas do YouTube e apresentam uma multiplicidade de suportes, linguagens e formatos em torno da representação das ocupações. Entre discursos em primeira pessoa, a partir dos dispositivos móveis operados pelos próprios estudantes, até as narrativas mais programáticas da mídia. Estas imagens nos ajudam a perceber as microrrelações entre os atores das manifestações.
}

(C) ETD-Educação Temática Digital Campinas, SP $\quad$ v.19 $\quad$ n.1 $\quad$ p. 3-25 jan./mar. 2017 
A eclosão das ocupações escolares promovidas pelos alunos da rede pública de São Paulo colocou em crise uma miríade de representações em torno de um dos mais capilarizados aparatos-aparelhos de Estado do país: a escola. Uma instituição que é vista (e com certa razão) como responsável por normatizar, cristalizar, petrificar desejos e devires. Por outro lado, esta mesma escola, que é alvo de críticas e comumente tomada como cenário dos mais "falidos", viu-se defendida e valorizada por aqueles que são seus atores centrais: os estudantes. Se não a escola como conhecemos, certamente a escola como utopia, como espaço de invenção de si e do mundo, de criação coletiva, do saber como experiência, da alteridade e da escuta.

Assim, a abordagem de tal acontecimento e sua força política e estética demanda certos cuidados dimensionais e estruturais para se evitar reducionismos. O caráter emergencial das ocupações, que ganham destaque nacional no fim de 2015 , se mostrou como ferramenta potente e disruptiva de ação pelos estudantes secundaristas. Algo que se espalhou como pólvora pelas redes sociais, mobilizando/motivando outros centros, outras pautas, diferentes narrativas/discursos, múltiplas imagens, novas lutas.

São linhas de força onde educação, a produção de imagens, a subjetividade contemporânea e a própria noção de imagem/montagem se relaciona de maneira tangencial e, por que não, conectada à dimensão mais concreta vinculada à experiência desses jovens em seus cotidianos. São particularidades que nos perpassam em contato com toda a gama de ações, discursos, linguagens e resistências que nos foram ensinados pelas ocupações e sua imediata ação política.

Nesse sentido, como repensar a própria noção de representação da escola e de seus agentes? O que seria "a escola", "o aluno", "o currículo" nesse novo cenário? Como as movimentações e posturas dos alunos provocam novas "montagens relacionais e pedagógicas" dentro de um recorrente discurso de desqualificação da escola pública (e a reboque, de seus alunos)? Será que ainda nos surpreendemos ao percebermos que a escola pública ainda pode ser positivada, digna de se defender com unhas e dentes, gritos e corpos? E o que dizer das imagens emergentes produzidas, entre o registro episódico, a necessidade de testemunho e seu caráter denunciativo, como prova das violações dos direitos estudantis? Ou ainda, como pensar essas imagens em tensão com a desgastada produção audiovisual televisiva e suas delicadas operações de montagem que a todo instante procuram, silenciosamente, defender o interesse dos já tão reconhecidos grupos e ideais políticos?

(C) ETD-Educação Temática Digital Campinas, SP v.19 n.1 $\quad$ p.3-25 jan./mar. 2017 
A maneira que encontramos para nos aproximar desses eventos foi por meio das imagens produzidas pelos alunos. Essas imagens se replicaram em algumas redes sociais, mostrando uma vasta gama de fragmentos, manifestos, performances artísticas, desejos, lutas e denúncias. Um esforço que uniu visibilidades e trocas, motivou alunos e alunas a se levantarem contra aquilo que não concordavam. Um exercício de voz, de se repensar as representações da educação, escola, políticas públicas, diversidade, respeito. Assim, nosso ensaio busca, em suas partes, conversar com algumas dessas imagens. Trazer suas vozes e performances para o texto e, por meio dos olhares fugidios e conflitivos que tais fragmentos provocam, buscar refletir sobre esse movimento e alguns de seus futuros desdobramentos.

\section{PLANO GERAL - AS ESCOLAS DE LUTA E O PLANO (DES)ORGANIZADOR}

CENA 2: Mano, lá é nossa casa... nosso lar... e eu sei que de lá sairão biólogos...médicos...até advogados e mais... eu amo até as tias da cantina...e tipo não dá pra sair assim do nada sem mais nem menos... não dá pra esquecer sua casa...seu lar e toda aquela família...não são de sangue e sim de coração...lá não somos amigos...somos uma família e sei que se todos agirmos juntos...não vão nos tirar de lá... não podem fazer isso, é nosso futuro que está em jogo e acho que falo por todos quando digo que não vamos deixar nossa casa nem nossa família para trás... \#força_carlao (EE. Carlos Gomes 25/09/2015).

No dia 23 de setembro de 2015, a Secretaria de Educação do Estado de São Paulo publicou uma nota em que apresentava uma proposta de reorganização da rede estadual de ensino. Para a surpresa da comunidade escolar, o documento expedido - sem a consulta das gestões de ensino, dos estudantes ou dos pais dos alunos e alunas - trazia uma medida vertical que impunha mudanças significativas no cotidiano escolar. De maneira sintética, a proposta de reorganização do modelo escolar definia a separação dos ciclos escolares ensino fundamental I, ensino fundamental II ou ensino médio - em cada unidade de ensino, a partir de 2016. Até então, as escolas poderiam compreender diferentes ciclos, integrando alunos de idades distintas em séries simultâneas, permitindo o convívio entre crianças e jovens, maiores e menores, e estimulando o intercâmbio sociocultural e intelectual. Com a nova mudança, cada escola deveria compreender apenas um dos ciclos de ensino, o que afetaria cerca de 1.000 unidades das 5.108 que compõem a rede estadual de educação, abarcando um total de 3,8 milhões de alunos regularmente matriculados ${ }^{4}$.

O plano capitaneado pelo secretário da Educação Herman Voodwald teve início após uma pesquisa realizada pela Fundação Seade (Sistema Estadual de Análise Dados), que apontou uma tendência de queda de $1,3 \%$ ao ano da população em idade escolar no estado

\footnotetext{
${ }^{4}$ O modelo segmentado por ciclos vinha sendo praticado até então por cerca de apenas $1 / 3$ das escolas em todo o estado. Com o plano reorganizador, 94 unidades de ensino seriam disponibilizadas e 311 mil estudantes diretamente afetados.
}

(C) ETD-Educação Temática Digital Campinas, SP $\quad$ v.19 $\quad$ n.1 $\quad$ p. 3-25 jan./mar. 2017 
de São Paulo. Basicamente, a pesquisa apresentava que, entre 1998 e 2015, a rede estadual de ensino "perdeu" 2 milhões de alunos. A justificativa da evasão escolar, somada à redução dos índices de natalidade nas duas últimas décadas, tornou a capacidade do parque escolar muito superior ao número de estudantes matriculados. Segundo a secretária-adjunta da Secretaria Estadual da Educação, Irene Miura, a questão econômica jamais norteou a proposta de reestruturação. A aposta na segmentação do ensino vinha acompanhada da melhoria dos equipamentos escolares e de ambientes melhores adaptados para o desenvolvimento dos projetos pedagógicos, oferecendo condições adequadas para preparar os estudantes para o mundo do trabalho ${ }^{5}$.

Dentre os principais pontos de crítica ao plano reorganizador é importante destacarmos alguns que nos parecem fundamentais para a imediata reação da comunidade escolar: 1) o projeto foi elaborado sem a consulta pública e divulgado através da imprensa, ignorando as gestões de ensino; 2) sua ação decorre por meio de decreto, o que contraria a natureza democrática da função executiva do Estado; 3) a mudança vem acompanhada de um corte significativo de verbas no já pequeníssimo orçamento da pasta da Educação, acarretando na demissão compulsória de um enorme contingente de professores temporários, além da rescisão de contratos com os trabalhadores terceirizados, normalmente nas áreas de alimentação, higiene e segurança; 4) superlotação das salas de aula já inchadas; 5) abertura das escolas públicas à iniciativa privada, a partir de parcerias público-privadas com a municipalização do ensino fundamental; 6) deslocamento dos estudantes até $1,5 \mathrm{~km}$ da escola de origem, em linha reta, algo que compromete particularmente as famílias com filhos em anos letivos com grandes intervalos, distribuídos agora em escolas diferentes e afastadas; 7) aumento da evasão escolar nos cursos EJA em função da redução da oferta de turmas no período noturno, obrigando os estudantes a se matricularem em cursos matutinos ou vespertinos ${ }^{6}$.

Rapidamente disseminado e retalhado por boa parte da opinião pública, o projeto de reorganização escolar foi duramente atacado nas redes sociais e também em parte pelos

\footnotetext{
${ }^{5}$ As falas da Secretaria da Educação do estado de São Paulo, através de seus representantes, merecem um estudo à parte, dada a sua complexidade. A total adesão ao ideal neoliberalista e a vocação da escola como um ambiente pré-empresarial marcam os discursos. Neste sentido, a escola torna-se um espaço voltado à aquisição do conhecimento para ser, no futuro, empregado no mercado de trabalho. Disto, excluem-se as possibilidades de pensar as ações formativas no presente, pois já as predeterminam a um horizonte do trabalho que deve ser naturalizado como o processo ideal a todos os que ingressam na vida escolar. Assim, a escola se mantém no estágio pré-fábrica / pré-empresa, de toda forma algo que não existe em si, mas atende a uma exigência do futuro, num ciclo infindável de presentificação do amanhã.

${ }^{6}$ Os dados e demais informações referentes ao plano foram extraídos de documentos oficiais da Secretaria de Educação compilados pelos boletins diários divulgados pela Apeoesp (Sindicato dos Professores do Ensino Oficial do Estado de São Paulo). Disponível em: http://www.apeoesp.org.br/noticias/manifestacoes-contra-a-bagunca-da-s-e/ . Último acesso em: 18 de janeiro de 2017
} 
sindicatos e associações de professores, assim como por grêmios e demais congregações discentes. Os protestos realizados por esses grupos ganharam consistência ao longo das semanas, sobretudo pelas constantes negativas por parte da Secretaria de Educação em reavaliar as ações, acima citadas, e dialogar com o setor.

A primeira escola a reagir ao "plano desorganizador", como foi chamado pelos estudantes, foi a Escola Estadual Diadema, no $A B C$ paulista, no dia 9 de novembro, cerca de um mês e meio após as primeiras declarações da Secretaria. No dia seguinte, a Escola Fernão Dias, em Pinheiros, Zona Oeste de São Paulo, foi tomada pelos estudantes tornandose uma espécie de "escola-modelo". Nos próximos dias, as ocupações passariam a se capilarizar de maneira não ordenada, e extremamente rápida, por todo o estado. Norteados pela palavra de ordem "não fechem nossa escola!", os estudantes ocuparam as unidades de ensino trancando portões, vigiando janelas e acessos, encastelando-se nas unidades e fazendo uma defesa radical pela sobrevivência do espaço escolar, agora em disputa.

O paradoxo se instalava: os estudantes, aqueles que saltam o muro para "matar aula", e que carregam todo o imaginário de vandalismo, algazarra e depredação contra o Estado centralizador organizado, protetor do patrimônio público e da boa norma, tinham seus papéis provisoriamente invertidos. Agora, eram os próprios estudantes que assumiam a gestão de suas escolas; enquanto o Estado, armado pela Polícia Militar, lançava sua primeira ofensiva contra grupos formados majoritariamente por crianças e jovens, menores de idade - com bombas, gases e todo o aparato bélico.

Desvinculados de partidos políticos, sindicatos ou mesmo de associações estudantis historicamente constituídas, como a UNE, as "escolas de/em luta" ganharam a adesão e apoio dos pais, de uma grande maioria de professores e diretores, assim como de várias camadas da sociedade civil. Em poucas semanas, um mapa disponibilizado no Google, alimentado voluntariamente em tempo real, sem "donos" ou chancelas, descrevia a situação das escolas ocupadas, com listas de itens de alimentação, limpeza e higiene, pedidos de solidariedade e apoio. Um formulário na web circulava entre advogados e professores que poderiam prestar seus serviços, sem honorários, auxiliando os estudantes com os processos jurídicos e ministrando aulas para garantir a manutenção do cotidiano de ensino. Imagens transbordavam das páginas do Facebook a partir de vídeos caseiros produzidos através de seus tablets e smartphones, precariamente editados ou imediatamente divulgados pelo Youtube como estratégias de proteção e combate. Páginas como O Mal Educado, Território Livre e Não fechem a minha escola tratavam de noticiar o

(C) ETD-Educação Temática Digital Campinas, SP v.19 $\quad$ n.1 $\quad$ p. 3-25 jan./mar. 2017 
que a mídia hegemônica insistia em ignorar, embora a pregnância do evento já guiasse a agenda setting de todo o país.

De alguma forma, era como se em muitos anos a pauta da educação estivesse verdadeiramente extravasando a seara acadêmica, os congressos e simpósios; abandonando os gabinetes das Secretarias e as salas dos diretores; fugindo dos diários de classe e debates curriculares; escapando às notas, presenças e faltas.

Os secundaristas das escolas ocupadas causaram um turbilhão de novas relações dentro do espaço escolar. Esses movimentos se desdobraram e levaram outros discursos e encontros para fora dos muros das escolas, penetrando o espaço público com uma energia pouco vista no ensino tradicional ou mesmo na experiência coletiva no urbano. Invadiu as avenidas fazendo-se visível no trânsito. Incitou as pautas jornalísticas e o debate político. Tocou mães, pais, adultos. Os estudantes, que antes tinham seus corpos trancafiados entre os muros da escola - num movimento diametralmente oposto à apoteótica destruição da instituição no final de Another Brick in the Wall, do Pink Floyd, hino à insubordinação gritavam que era preciso que todos se mobilizassem em torno da educação. Que as paredes da escola, suas formas de relação - da merenda à vigilância, do currículo à gestão das vidas no ensino - precisa da atenção de todos. Um conhecido provérbio africano diz que é preciso uma aldeia inteira para educar uma criança. As crianças pareciam estar levando esse provérbio a sério.

\section{PLANO MÉDIO - ENTRE OS MUROS: RETOMAR A ESCOLA, CONSTRUIR AUTONOMIAS}

- Eu sou o meu próprio chefe. A Infância de Ivan, Andrei Tarkovski

CENA 3: o segmento é uma montagem com imagens de uma matéria publicada pela Folha de São Paulo $e$ retirada do ar após uma visita do governador Geraldo Alckmin e sua assessoria de imprensa à redação do jornal. As imagens apresentam jovens dentro das ocupações, alguns traços do abandono do espaço, agora recuperado e gerido pelos próprios alunos. Em uma tomada fechada, vemos uma vassoura que, empunhada por um dos jovens [que não aparece em destaque no plano], "limpa" o espaço do quadro. Outros cozinham e preparam alimentos [lavando, selecionando, cortando] na cozinha da escola. As imagens são acompanhadas pela releitura de um rap que se transformou em "Escolas de Luta", por MC Foice e Martelo. A letra começa com uma conversa entre os dois garotos: "-E aí salve Martelo?/ - E aí foice, firme?/-Firme não né tio? Cê é loko, Tá aí o Alkimin fudendo aí os estudantes/ - Eh, to vendo, vai fechar uma pá de escola... fecha escola e abre cela..Tô nem entendendo...mas fiquei sabendo que os estudantes tão todo organizado, né não?! [entra a música] "O Estado veio quente, nóis já tá fervendo/Quer desafiar? Não tô entendendo/Mexeu com estudante, vocês vão sair perdendo".

(C) ETD- Educação Temática Digital Campinas, SP $\quad$ v.19 $\quad$ n.1 $\quad$ p. 3-25 jan./mar. 2017 
Pela manhã, aula de yoga e debate sobre o Islã e a representação do mundo árabe pelo Ocidente. À tarde, matemática, geografia e música. À noite, cineclube com roda de conversa sobre Direitos Humanos. No portão, um garoto e uma garota se revezam entre a guarda. Aos fundos, um grupo de jovens empunhando vassouras, rodos e mangueiras tratam de limpar a quadra, onde novas atividades serão desenroladas após o almoço. $\mathrm{Na}$ cozinha, umas doze mãos dividem-se entre as grandes panelas, cebolas, tomates, pacotes de macarrão e molho, salsichas e legumes. No banheiro principal, misto, meninos e meninas desinfetam pias e privadas ${ }^{7}$.

Em um de seus últimos escritos, Paulo Freire (2014) afirmou que não há prática educativa que escape a certos limites - ideológicos, epistemológicos, políticos, econômicos, culturais. "Creio que a melhor afirmação para definir o alcance da prática educativa em face dos limites a que se submete é a seguinte: não podendo tudo, a prática educativa pode alguma coisa" (FREIRE, 2014, p. 113). O cenário de organização dos estudantes e sua manutenção do cotidiano escolar, agora sem a coordenação de mestres e servidores, torna nítida a sensação de que a não imposição de limites cria as condições para o caminho de uma prática pedagógica emancipadora. Responsáveis então por todas as funções, os estudantes deixam de ser alunos, em seu espaço contraditório de conforto-revolta, para assumirem a posição de um devir-aluno. Aluno que não está mais sentado à espera do saber transmitido pelo professor, como um receptáculo de informações privilegiadas que o conduzirão a uma transformação interna e, no melhor dos mundos, a mudanças nas relações com a coletividade, produzindo enfim as transformações sociais tão almejadas. Aluno-porteiro, aluno-merendeiro, aluno-faxineiro, aluno-diretor, aluno-inspetor. Aluno e. A desenraização total do sujeito aluno, do seu lugar fixo de representação, em nome de uma subjetividade aluno, que se constitui a partir do engajamento em atividades naturalmente apartadas do processo de formação pedagógico.

Assim, é possível pensar nas ocupações como um jogo onde dados problemas estão postos, múltiplos elementos tornam-se disponíveis, cabendo aos estudantes colocá-los em relação, ordená-los e fazê-los funcionar. Na ocupação enquanto jogo, os limites

\footnotetext{
7 "Além de aulas e discussões sobre temas mais vinculados ao universo da educação formal, têm acontecido debates, exposições, atividades físicas, de lazer, entre outras. Como alguns poucos exemplos da rica diversidade desta movimentada rotina, podemos citar: debates sobre a Revolta dos Pinguins chilena e a Revolução Curda que atualmente ocorre em Rojava; aulas públicas sobre a educação no Brasil e em São Paulo; formações sobre a questão de gênero e o feminismo; debates sobre formas alternativas de educação; oficinas de mídia alternativa; conversas com movimentos populares; aulas de circo, de dança, de teatro e jogos coletivos. Fora dos portões das escolas, outras ações têm sido encampadas, marcadamente as marchas pela cidade e o trancamento de ruas e avenidas". Disponível em: http://anarquismosp.org/2015/12/04/luta-e-organizacao-na-ocupacao-das-escolas-em-sao-paulo. Acesso em: 12 de fevereiro de 2016.
}

(C) ETD-Educação Temática Digital Campinas, SP $\quad$ v.19 $\quad$ n.1 $\quad$ p. 3-25 jan./mar. 2017 
apresentam-se tais como regras - ao mesmo tempo em que restringem as possibilidades de atuação no tempo e no espaço, produzem uma virtualidade, um sem número de modos de conferir movimento ao todo. Poderíamos imaginar algumas regras que, de maneira não sistematizada e intercambiável, definiram a grande parte das ocupações. Regra 1: ninguém entra, a não ser que o novo integrante produza algo para a comunidade recém-formada. Regra 2: é preciso aproveitar e reaproveitar os recursos e fazê-los render, sem desperdício. Regra 3: todos desempenham funções, distribuídas de maneira aleatória. Regra 4: não há distinção entre gêneros - todos podem tudo. Regra 5: não há líderes perenes, apenas comandos provisórios e esfaceláveis, substituíveis. Regra 6: a escola é o todo ${ }^{8}$.

Como pensar uma pedagogia sem questionar a arquitetura das escolas, a circulação dos sons, o transporte dos alunos, as estruturas administrativas, [...] a relação com o estado, a função da direção e a relação com a tecnologia, as tensões com o capital? (MIGLIORIN, 2015, p. 182).

As ocupações apresentam como estratégia uma espécie de engajamento pacífico, mas que não ocupa o espaço de maneira passiva (no sentido de apenas defender um território pela simples presença inerte dos corpos). Sua ação é localmente transformadora preservando, cuidando, se incorporando e transformando os tempos e espaços do território da escola. Se na atividade escolar cotidiana os lugares atribuídos aos alunos, como também aos demais profissionais, é estabelecido em função da atividade que desempenham, estamos aqui no cerne das discussões travadas em torno da compreensão da dimensão estética na política.

A visibilidade e a inteligibilidade dos acontecimentos é dada em função do lugar que cada sujeito ocupa no sensível (RANCIÈRE, 2012). Tratando-se dos alunos, sabemos que os comportamentos esperados são: sentar, quando lhes for ordenado; perguntar, quando lhes for permitido; anotar, tudo veloz e imediatamente; correr, pular, sujar, gritar; no intervalo. $\mathrm{Na}$ ocupação, os espaços e os corpos assumem outras posturas. Os acessos negados - sala do diretor, secretaria, almoxarifado, dispensa - tornam-se passagens fluidas. O tempo, não mais compartimentado pela campainha ou o sinal que interrompe ou dispara o fluxo, ganha uma espécie de autonomia onde outras divisões podem ser criadas, com outros padrões ou mesmo a recusa completa deles.

A escola ocupada não é um espaço fechado. Os círculos de conversa estão abertos. Um novo espaço se configura. Ele agora é infiltrado por outros agentes que enriquecem e

\footnotetext{
${ }^{8}$ Do chuveiro quebrado à merenda escolar, a autogestão das ocupações engaja os estores em todas as atividades da vida escolar. Disponível em: http://www1.folha.uol.com.br/educacao/2015/12/1712999-ha-um-mes-nas-escolas-alunosorganizam-limpam-cozinham-e-ate-instalam-chuveiros.shtml?cmpid=fb-uol Acesso em: 28 de fevereiro de 2017.
}

(C) ETD-Educação Temática Digital Campinas, SP $\quad$ v.19 $\quad$ n.1 $\quad$ p.3-25 jan./mar. 2017 
corroboram com as ações dos alunos, seja por professores voluntários que se disponibilizam em compartilhar suas experiências e conhecimentos em aulas abertas, seja por $\operatorname{artistas}^{9}$ que visitam as ocupações e (se) movimentam artisticamente junto aos alunos formando festivais, ocupações culturais e compartilhando seus modos de vida ${ }^{10}$.

Busca-se uma outra estética pautada pela performatividade dos corpos nas ocupações. Neste sentido, Hakim Bey (2004) e o seu conceito de Zona Autônoma Temporária - ou TAZ (em inglês), nos ajuda na abertura de significados desses movimentos. Essas zonas são entendidas como espaços independentes onde a troca de subjetividades, experiências, linguagens, informações e tudo o mais que interesse acontece de maneira descentralizada, forjando uma coletividade que deseja construir "enclaves livres" de contato. A localização da TAZ é temporária e espontânea, mas concreta no tempo e no espaço. Ela existe tanto no espaço virtual da informação (como uma contra-net, utilizando das redes de comunicação no espaço da internet como instrumento de trocas) quanto no mundo real. A efemeridade é uma característica marcante da TAZ, pois, ao não instituir vínculos e/ou estruturas, evita que o movimento possa ser capturado pelo aparelho de Estado, sendo assim, esmagado.

Uma das preocupações da TAZ é que a experiência de existência se dê de forma imediata, sem mediações. "A TAZ é utópica, no sentido que imagina uma intensificação da vida cotidiana, ou, como diriam os surrealistas, a penetração do maravilhoso na vida" (BEY, 2004 , p. 35). Ela é uma crítica à estrutura rígida e representacional do Estado, sendo uma espécie de levante que não o confronta diretamente, pois sua proposta é construir algo para além das estruturas organizacionais tradicionais do Estado (outras relações e horizontalidades).

Eu particularmente detestava a escola, desculpa a sinceridade, mas eu detestava a escola por ela ser um ambiente muito opressor [...], só que eu detesto a escola mas eu acho que quem faz a escola somos nós [...], porém, tipo eu falo que eu não gosto assim só que é a minha escola, sabe, tipo eu quero estar aqui, eu quero mudar esse costume chato dos professores entrarem aqui e jogarem qualquer coisa na lousa, porque a escola pode ser do jeito que for mas é um ambiente nosso que a gente tem que lutar por ele [...] EE Maria José (CAMPOS; MEDEIROS; RIBEIRO, 2016, p. 34).

\footnotetext{
9 Disponível em: https://catracalivre.com.br/sp/agenda/indicacao/escolas-ocupadas-promovem-virada-cultural-comcriolo-paulo-miklos-maria-gadu-e-outros/ Acesso em: 15 de fevereiro de 2016.

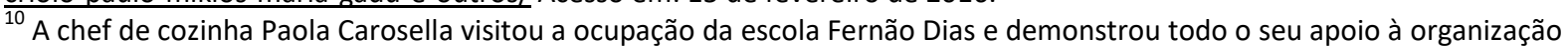
dos alunos de maneira espontânea. Disponível em: http://noticias.terra.com.br/educacao/paola-carosella-cozinha-emocupacao-da-escola-estadual-fernao-dias,277e27136cc4cdafe10487e0acff5665geeokp0z.html Acesso em: 15 de fevereiro de 2016. Durante o período das ocupações, artistas como Criolo, Paulo Miklos, Emicida, dentre outros visitaram as ocupações, promovendo performances em solidariedade aos estudantes.
}

(C) ETD-Educação Temática Digital Campinas, SP $\quad$ v.19 $\quad$ n.1 $\quad$ p. 3-25 jan./mar. 2017 
Levante, por sua vez, traz a ideia de "levantar". Algo que transgrida a noção de ordem e também desobediência: Levante!/Não se levante! Frente a esta dicotomia, pensar que os jovens das ocupações se "levantaram" contra as propostas de reorganização postas pelo Estado, também traz a ideia de uma ação que eclode da necessidade interna de subverter, de colocar uma recusa imediata à violência imposta pelo aparato disciplinar. A metáfora é tocante certamente, mas o levante, não apenas como imagem, é uma subversão pacífica que desloca a autoridade do Estado legislador frente aos seus cidadãos, expondo suas veias autoritárias.

Assim, o levante - levantar - também é uma operação do próprio corpo. Antes submetido ao regime dos dispositivos disciplinares, (o corpo) passa a ser, agora, detentor de suas articulações motoras, senhor de seus próprios gestos. Sem a presença da tecnologia dos confinamentos, a imediata sensação é de que o levante levaria à recusa de toda e qualquer forma de assimilação às mesmas normas. O que as ocupações nos mostram, contudo, é a produção de diferentes formas de gestão da estrutura e dos códigos escolares. Como se o poder, não mais hierarquizado, se esvaziasse em função de uma molecularização de suas operações. Um poder que não mais se encarna na figura de um chefe ou de um líder, tampouco do carrasco ou de outros símbolos que representam o opressor. Mas que, ainda assim, tolera a organização, a divisão do trabalho, a rotina, o lazer, etc.

As zonas autônomas instituídas pelos alunos corrompem as hierarquias e promovem outras linhas, estabelecendo uma horizontalização das organizações e decisões. As ocupações inserem "um outro currículo" como possibilidade, seja por meio das rodas de conversa temáticas promovidas pelos alunos junto a professores e especialistas convidados, do cuidado com o espaço, seja pela própria reorganização da estrutura temporal da escola. Os espaços ainda possuem uma ordem, mas que não respeitam, necessariamente, as fronteiras instituídas pelo aparelho de Estado. Agora, as linhas são desenhadas pelos seus habitantes-agentes. São apagadas, redesenhadas, redistribuídas. As decisões são polifônicas e compartilhadas. Tudo percorre a esteira do diálogo como instrumento político (confrontando a ação impositiva dos entes governamentais).

(C) ETD-Educação Temática Digital Campinas, SP $\quad$ v.19 n.1 $\quad$ p.3-25 jan./mar. 2017 


\section{CLOSE-UP - DA LUTA POR VOZ AOS GESTOS POLÍTICOS}

CENA 4: Uma sala cheia de alunos. Todos estão sentados com os olhos vendados com faixas negras. A câmera, em panorâmica, cobre a sala de um lado a outro. Ao fundo vemos três alunos, de costas, que marcam o ritmo, em primeiro momento lento, em instrumentos de percussão. Todos os alunos começam a cantar uma versão adaptada da música "Cálice", de Chico Buarque:

"Como é difícil acordar calado, Se na calada da noite eu me dano Quero lançar um grito desumano Que é uma maneira de ser escutado

Esse silêncio todo me atordoa Atordoado eu permaneço atento Na arquibancada pra qualquer momento Ver emergir o monstro da lagoa

Está na hora de crescer, passar a limpo este país Devolver pra nossa gente o dom de ser feliz

Onde é que está nosso futuro e nosso país Que só promete mas só faz tirar do povo Onde é que está nosso direito de viver

Nosso direito pra fazer um mundo novo

E as crianças sobem livres sobre os muros Ensine os sonhos que não podem amar sem dor E que o passado abra o presente e pro futuro

É curioso perceber como uma das críticas reincidentes dos estudantes girava em torno da frase: "O Estado não nos ouve". Vale a pena aqui retomar um conceito importante para tentarmos entender as relações que se esboçam a partir da cena supracitada, da distinção entre as noções de política e polícia (RANCIÈRE, 1996). Ao reconhecer que o Estado não os ouve, os estudantes sabem que isso não decorre de sua (in)capacidade de fala. Ou melhor, sabem que dizer quais são suas demandas - ou espernear por elas - não significa que as mesmas sejam reconhecidas enquanto tais. É assim que os cartazes e os gritos de guerra dos estudantes convertem-se em gestos que se aproximam de operações que estão no campo da polícia. Nesta perspectiva, os estudantes atuam a partir dos elementos postos pelo Estado, jogam com as ferramentas que Ihes são ofertadas, solicitando um espaço para que a sua fala possa existir e, então, adquira a espessura política almejada. É como se dissessem: "Somos crianças, somos estudantes, o que vocês estão fazendo é errado! Há uma lei que nos protege e vocês precisam pautar sua conduta por ela". Trata-se de uma noção que vem acompanhada da crise da boa consciência, própria

(C) ETD-Educação Temática Digital Campinas, SP $\quad$ v.19 $\quad$ n.1 $\quad$ p. 3-25 jan./mar. 2017 
inclusive de uma crença ingênua de que a política pode ser eventualmente conduzida por pessoas equivocadas que não sabem bem o que fazem... essa ingenuidade estaria norteada pela perspectiva de que aqueles que administram a educação teriam um melhor diagnóstico e, portanto, agiriam em conformidade ao desejo dos estudantes ${ }^{11}$ caso soubessem o que eles pensam. Nesta chave, os gritos dos estudantes são facilmente convertidos em falas mudas pelo aparelho de Estado na forma de seus representantes.

A cena política não é assim um lugar de acordos que organizam relações e poderes, mas de irrupção de seres falantes, de línguas e entonações em um universo que perde suas estruturas e seu caráter policial de distribuição de lugares já dados, para se haver com uma suspensão dos lugares que garantiam a desigualdade. A política não está dada a priori, como parte da natureza humana. As partilhas que se veem estáveis, onde não há mais o lugar de uma subjetividade excessiva, que perturbe a partilha, são justamente os lugares em que a política tende a desaparecer (MIGLIORIN, 2008).

Ao reconfigurar o espaço sensível das escolas, o que os estudantes conquistam é o reconhecimento de que a ação política se efetiva propriamente na redistribuição do que é dado a ver e dizer. Emancipados corpórea e intelectualmente, a disputa não se dá mais na ordem discursiva da representação política. Ou seja, não se trata então de fazer com que o Estado finalmente os ouça. Ela é propriamente um campo de invenção, onde a cena que se institui é em si mesma um acontecimento. É certo que as ocupações foram motivadas pela tentativa de negar o esfacelamento de unidades físicas de ensino. Por outro lado, a circunstância criada pelos estudantes, o modo de funcionamento da máquina-escola, mostrou-se um instrumento pedagogicamente muito superior à investida por um plano distante governamental que acredita em uma "educação de qualidade", que poderia se revelar, ou não, concreto no futuro. Se a política é mesmo uma cena onde novos sujeitos se inscrevem, as escolas foram o palco ideal para a erupção da subjetividade aluno, não mais submetida à medida e desmedida estatais, da antiga representação forjada para estes corpos e mentes.

O que está em questão na experiência política não é um fim mais elevado, mas o próprio ser-na-linguagem como medialidade pura, o ser-em-um meio como condição irredutível dos homens. Política é a exibição de uma medialidade, o tornar visível um meio como tal. Ela é a esfera não de um fim em si, nem dos meios subordinados a um fim, mas de uma medialidade pura e sem fim como espaço do agir e do pensamento humano (AGAMBEN, 2015, p. 107).

\footnotetext{
${ }^{11}$ Poderíamos fazer uma aproximação de como esse modus operandi da ação policial se configura, por vezes, como a própria compreensão da alienação no campo da arte ou da educação. "Não sabem o que fazem", diriam aqueles que acreditam no despertar da consciência pela educação transformadora, a partir dos bons objetos. A respeito deste tema uma outra abordagem das ocupações parece ser necessária.
}

(C) ETD-Educação Temática Digital Campinas, SP $\quad$ v.19 $\quad$ n.1 $\quad$ p.3-25 jan./mar. 2017 
Como meios sem fim, em nossos próprios termos, as ocupações não trouxeram consigo as mesmas pautas de reivindicações a serem atendidas - tais como as greves universitárias, que se mostraram inclusive inócuas do ponto de vista das conquistas para a classe, a partir de dado momento. Tampouco conclamavam a formação de uma nova escola. Sua pauta se efetivava no presente da experiência coletiva projetada pelos estudantes. "A política faz existir aquilo que, sem ela, não existiria: em nossos próprios termos, o comum, como uma totalidade aberta, provisoriamente definida" (BRASIL, 2010, p. 7). Inventar o comum, nos parece, foi o ato político que fez das ocupações uma máquina incompreensível aos manuais de funcionamento do Estado. Um circuito de afetos onde o que estava em disputa era a própria invenção de si mesmo enquanto sujeito.

\section{CAMPO E CONTRACAMPO: ACONTECIMENTO E REPRESENTAÇÃO}

"É uma decisão do juiz que tem que ser cumprida. Decisão de juiz, a gente não contesta. $\mathrm{O}$ juiz manda em todos nós. Em mim, nos policiais, no Claudio e em vocês. Apesar de vocês serem menores de idade, vocês respondem por ato infracional", diz uma mulher, loira, na faixa dos quarenta anos, num tom didático e "maternal". A câmera enquadra seu rosto em close, enquanto ao fundo vemos outras pessoas que também assistem ao evento. Por vezes, a câmera escapa e percebemos que a mulher se dirige a um grupo de estudantes que, por detrás das grades, ouve e rebate os argumentos. Ela segue no tom instrutivo, como se ao falar vagarosamente estivesse garantindo a máxima compreensão dos jovens - ainda que o uso constante de jargões jurídicos contradissesse esse aparente desejo de estabelecer um diálogo efetivo com os estudantes. A mulher prossegue: "Nós estamos querendo resolver a situação de uma forma pacífica. A manifestação de vocês é assegurada constitucionalmente, só que o juiz diz assim: nos termos da constituição o direito de ir e vir é legítimo. O direito meu termina onde começa o direito seu". Com uma caneta na mão, a mulher segue como se estivesse à frente de uma sala de aula, apresentando os termos que definem a ilegalidade da ocupação acompanhada da solicitação de que os jovens deixem a escola ${ }^{12}$.

Aos poucos o clima de indisposição diante dessa figura vai tomando não apenas o lado de lá do portão, mas também os cidadãos que, como nós espectadores, se colocam no contracampo dos estudantes. A esta altura já sabemos que a mulher é uma oficial de justiça e que tem em mãos um documento que pede a reintegração de posse da escola Dr. Clybas Pinto Ferraz, no bairro de Santa Cecília. "Eu sei que quando a gente é novo, e eu já fui nova

\footnotetext{
${ }^{12}$ Agradecemos a Roberto Robalinho pelo compartilhamento deste vídeo.
}

(C) ETD-Educação Temática Digital Campinas, SP $\quad$ v.19 $\quad$ n.1 $\quad$ p. 3-25 jan./mar. 2017 
como vocês, a gente tem um ideal muito forte dentro da gente, graças a Deus, e é isso o que faz o nosso país andar, não é?". "Andar pra onde?", rebate uma estudante no fora-dequadro. "Ou não, né? No Brasil a gente não tem voz", diz uma jovem que durante toda a fala da mulher manteve-se à frente do grupo de estudantes. Ela responde com um suspiro que parece conter um misto de indignação e consciência de que a fala da oficial de justiça reproduz uma espécie de lugar-comum que, ali, é usada como ferramenta para conscientizá-los.

O plano-sequência de dezenove minutos progride com o embate dos estudantes, que aos poucos vão se agrupando em frente ao portão; a mulher, referenciando o tempo todo as medidas legais e a imposição judicial; e os pais e professores que, apoiando os estudantes, insistem que o processo apresenta irregularidades e que não há respaldo jurídico para o pedido de reintegração de posse. A discussão passa ao largo dos estudantes. Eles, totalmente despossuídos dos recursos intelectuais para debater com a oficial de justiça, seguem exigindo explicações, que são rebatidas com insistentes "não sei" da mulher que encontra sua defesa no magistrado - "o juiz mandou, temos que obedecer".

Durante toda a ação, a câmera jamais penetra o espaço dos estudantes. O embate entre o campo e o contracampo estabelece a relação às sensibilidades que estão em disputa. De um lado, os estudantes, que reclamam o direito da palavra. Do lado de fora, o Estado, através de seus representantes - a oficial de justiça, o conselheiro tutelar, os advogados - deliberam sobre aqueles que estão ali dentro. Enquanto a mulher tenta explicitar a situação informando que eles devem deixar a escola, desocupando-a imediatamente, em conformidade com o que prega a lei, os estudantes respondem com palavras de ordem - "onde estão os nossos direitos?" Curioso aqui pensar que os estudantes, ao reivindicarem a presença do conselho tutelar ou mesmo de seus direitos enquanto menores, restituem o Estado e suas formas de "assujeitamento".

Desconhecemos quem produz a imagem; a câmera aparece como uma espécie de registro sem corpo. Como no jornalismo mais cotidiano, a singularidade daquele que gera as imagens deve ser invisibilizada em nome de uma maior pregnância do evento. Porém, se no jornalismo isso se deve aos critérios de veracidade da notícia e do princípio da imparcialidade narrativa, aqui, esse distanciamento nos aproxima da emergência das imagens produzidas nas manifestações de junho de 2013. Como se essas câmeras fossem também espécies de testemunho da experiência. Formas de garantir o vivido através da força indicativa da imagem.

(C) ETD-Educação Temática Digital Campinas, SP $\quad$ v.19 n.1 $\quad$ p. 3-25 jan./mar. 2017 


\begin{abstract}
As imagens se aproximam, em certa maneira, ao conceito que François Jost (2007) nomeia como "imagens violentas": uma violência contida nos choques de percepção que revelam a experiência de quem opera essas imagens, possibilitando ao espectador uma tentativa de "viver o acontecimento, porque ela constrói, por sua enunciação, uma humanidade atrás da câmera". Humanidade sem rosto, diríamos. (JOST apud PADOVANI; PIPANO, 2015).
\end{abstract}

Em um de seus mais célebres ensaios, intitulado "Montagem Proibida", o crítico francês André Bazin (1985, p. 62) escreveu que "quando o essencial de um acontecimento depende de uma presença simultânea de dois ou mais fatores de ação, a montagem fica proibida". Em nome do respeito à unidade espaço-temporal, sobretudo, a montagem estaria assim proibida de exercer o seu papel fundamental com o risco de certo comprometimento do real. "As presentes observações não têm por objeto a forma, mas a natureza do relato ou, mais exatamente, certas independências da natureza e da forma" (ibidem). Apesar de Bazin fazer referência ao campo das imagens jornalísticas - seus estudos detinham-se na especificidade cinematográfica -, sua percepção sobre a impossibilidade da fragmentação e interrupção de determinado evento nos tocam diante da sequência do embate entre os estudantes e a oficial de justiça. Algo que remete ao documentário direto, Like a fly on the wall, que privilegiou o plano-sequência como uma unidade dramática em detrimento da fragmentação e dos cortes acelerados, como se a câmera se pusesse a observar o mundo à medida que os fatos acontecem, com os vacilos e lacunas próprios desse olhar urgente, porém necessário.

A ausência de corte e o prolongamento de toda a ação criam um arco dramático que varia entre momentos de intensidade e violência de ambas as partes, sem termos o ponto de vista nunca alterado dessa perspectiva distanciada e não participativa; há silêncios e uma quase total incompreensão, para nós espectadores, diante do que acontece. A tentativa de conciliação inicial do conflito pouco a pouco se desfaz e dá lugar ao transbordamento da impossibilidade fática entre os jovens e os representantes do poder. Se, inicialmente, eles tentam negociar pelas formas do Estado, aos poucos compreendem que o que se expõe ali é a própria fratura dessa negociação - o desentendimento entre as partes que veem o mesmo mundo, mas cuja semântica é incompartilhável.

Ao recursar a montagem, o que o plano-sequência faz é incluir no mesmo quadro, em um só tempo, o campo e o contracampo. Já a polarização dessa cena - as crianças contra o Estado - em dois blocos de imagens, desnudaria rapidamente a fragilidade do grupo de estudantes frente ao poder estatal. Despossuídos das competências retóricas para o debate, a inclusão dos agentes no mesmo espaço do conflito produz um singular estranhamento. Estranhamento que surge com o fato de que as crianças exigindo a

(C) ETD-Educação Temática Digital Campinas, SP v.19 $\quad$ n.1 $\quad$ p. 3-25 jan./mar. 2017 
presença do Estado - quando a nossa aparente sensação é de que tudo ali incita à supressão completa das forças legitimadoras do poder. Da perda da infância à dessubjetivação da funcionária do governo que diz que também já teve desejos, que já fora criança, e agora já não é.

Nos minutos finais, os jovens deixam o portão e se agrupam em frente à escola. 0 tom antes calmo e sereno da mulher dá lugar a gritos incisivos. $O$ acordo não efetivado resulta na tentativa de imposição da palavra legal pela força. Os estudantes, por outro lado, respondem com gritos de "Ih, fora!", com igual violência. Curiosamente, o mandato apresenta uma irregularidade cuja leitura atenta feita por um advogado, pró-estudantes, explícita a nós, espectadores. Os estudantes celebram, a mulher deixa a porta da escola visivelmente contrariada. A câmera, antes de finalmente fazer o corte, ainda capta os estudantes celebrando eufóricos.

\section{FADE OUT - MICROCENAS PARA UM NOVO ENQUADRAMENTO: AS OCUPAÇÕES COMO UMA EXPERIÊNCIA DE AUTONOMIA: PODEMOS SONHAR COM NOVOS ESPAÇOS DESEJANTES?}

Com o início do ano de 2016, e com a iminência do retorno das aulas, vemos que algumas conquistas foram feitas e outras batalhas foram iniciadas. A experiência de autonomia e o exemplo das ocupações foram marcos nas estratégias de resistência frente a um presente impossivel. Um presente que restringe e sufoca, que retira vozes múltiplas.

Para o educador português José Pacheco (2014), aprender compreende todo e qualquer espaço (seja ele real ou virtual). A todo momento aprendemos, nos mais diversos espaços e tempos constituímos processos de aprendizagem significativa, integradora, diversificada, ativa, socializadora. Nesse sentido, urge reavaliar os conceitos de espaço e tempo de aprendizagem para além dos muros físicos da escola. Busca-se a defesa de uma liberdade, da incorporação daquilo que a escola capturou dos conhecimentos da comunidade, recolocando-a como parte de uma rede de aprendizagem colaborativa.

"Ocupar e resistir" passa a ser um novo lema. Uma outra forma de se posicionar frente aos mais violentos descasos e retiradas de direitos em um cenário catastrófico politicamente. A aprendizagem passou a ocupar novos percursos, outros espaços. A busca por autonomia pelos estudantes começou a ser vista por setores conservadores da sociedade brasileira, principalmente por uma classe média insatisfeita e raivosa, como

(C) ETD-Educação Temática Digital Campinas, SP v.19 $\quad$ n.1 $\quad$ p. 3-25 jan./mar. 2017 
doutrinação $o^{13}$. Tais movimentos conservadores acabam por defender silenciamentos (novamente), a muitos dos temas que surgiram na pauta de interesses dos secundaristas, como: políticas contra homofobia, racismo, desigualdades sociais e demais questões que tensionam as novas sociedades. O que vemos é uma contrarresposta externa, de entidades e grupos da sociedade civil, que enxergam os movimentos aflorados pelos secundaristas como uma afronta ao que seria o papel da escola e da educação.

São questões que acabam servindo de "bandeira" para retrocessos defendidos por setores conservadores no intuito de moralizar o espaço escolar. Os discursos tensionados visam uma escola que não seja habitada por corpos, desejos, diversidades e pluralidades; mas que se ocupem de questões racionalistas e técnicas em situação de produção, em uma condição de assepsia. Para além das defesas ideológicas, os discursos meramente pautados por um ideal técnico sufocam o campo da reflexão crítica que busca cidadãos transformadores do mundo. O risco é perpetuarmos uma escola subalterna, dividida em campos de saber distintos às diferentes classes sociais via tutela legal sob justificativas econômicas de corte de gastos. Tais medidas estão sendo construídas de forma diretiva e isolada, a bem ver as questões referentes à reforma do ensino médio feita via decreto (lei $\left.13.415 / 17^{14}\right)$, excluindo a sociedade civil das discussões sobre os interesses em questão. Outras medidas agravam a depreciação do fazer docente, retirando a sua relativa autonomia na abordagem dos temas curriculares por meio da replicação de manuais,

\footnotetext{
${ }^{13}$ O projeto intitulado "Escola sem partido" é um desses exemplos de proposta que busca silenciar a possibilidade de problematização desses temas. Este projeto parte da ideia de que o professor, por ter um público cativo de alunos, utilizaria tal exclusividade para "doutrinar" ideologicamente essas "mentes despreparadas" para causas vinculadas à esquerda. O "Escola sem partido" foi idealizado por Miguel Nagib e demais entidades conservadoras da sociedade civil, que encontraram acolhimento em partidos e políticos de mesma linha ideológica. Assim começaram a difundir tal projeto como "propostas de lei ordinária" em diversas câmaras de vereadores e deputados. O projeto inclusive assumiu caráter federal, sendo transformado no projeto de lei 193/2016, proposto pelo senador evangélico Magno Malta. Ao todo, o "Escola sem partido" foi proposto em cerca de onze estados e atualmente aguarda o julgamento de sua constitucionalidade. (Fonte: http://especiais.g1.globo.com/educacao/2016/'escola-sem-partido'/último acesso em fevereiro de 2017).

14 Fonte: http://legis.senado.leg.br/legislacao/ListaTextolntegral.action?id=251273\&norma=270661. Último acesso em 20 de fevereiro de 2017.
}

(C) ETD-Educação Temática Digital Campinas, SP v.19 n.1 $\quad$ p.3-25 jan./mar. 2017 
treinamentos e materiais didáticos unificados ${ }^{15}$ apresentados por setores fortemente ligados à iniciativa privada que atuam no ramo da educação ${ }^{16}$.

Em meio a todos os desafios, resta nos reter à resistência dos secundaristas e à defesa do espaço público como direito. A coragem desses estudantes mobiliza, permanece nas ocupações das universidades, polos de cultura e demais espaços considerados públicos e catalizadores de desejos e esperanças.

\begin{abstract}
Os olhos falam...os olhos choram, lágrimas de desespero, de medo e pavor. Mas a esperança ainda está ali. Foi dado início a uma onda de repressão, onde os policiais (representantes do Estado) invadem escolas, aterrorizam jovens que estão em luta por uma educação de qualidade, e que são contra uma "reorganização", que não foi debatida com os principais interessados, os alunos. A luta continua, "não tem arrego". Não precisamos usar de força física, os sprays de pimenta, nossas armas são outras. A aluna L., com canetas na mão, afrontou a polícia na manhã de ontem dizendo" MINHA ARMA É OUTRA!" EE Maria José- 01/12/2015 (CAMPOS; MEDEIROS; RIBEIRO; 2016, p. 226).
\end{abstract}

Em meio às disputas por transformações nos currículos da educação básica, cortes no orçamento e outros cenários sombrios, passamos vislumbrar como essas múltiplas experiências construídas pelos secundaristas poderiam transformar novas rotinas na escola. Nos resta pensar em que medida aquilo que é visto como "excesso" na escola, como as aulas de cinema ou de música, shiatsu e outras experiências extraordinárias poderiam, rapidamente, se transformar em moedas para uma educação ainda mais neoliberal, onde o estudante define aquilo que quer e quando quer, como um produto diferenciado, destinado a poucos. De que maneira essas ações, que agora surgem oxigenando o antiquado currículo, são rapidamente integrados aos processos de subjetivação do capitalismo contemporâneo em que a satisfação do desejo individual é um dos maiores operadores? Tornar a escola mais divertida, com entretenimento, música, imagens e sons, vem sendo uma das principais

\footnotetext{
${ }^{15}$ A base nacional comum visa um conjunto de orientações de conteúdos para os currículos de escolas públicas e privadas em todo o território nacional, para todos os seguimentos. Alicerçado em competências e habilidades gerais e específicas, o projeto (que ainda está em discussão) propõe um sequenciamento de conteúdos e habilidades que deverão ser incorporados pelos programas federal, estadual e municipal educacionais. (Fonte: http://basenacionalcomum.mec.gov.br/\#/site/inicio. Último acesso em 20 de fevereiro de 2017).

${ }^{16}$ Certos grupos privados de educação, aliados a outros setores da sociedade civil, constituem uma organização que visa oferecer propostas sobre quais seriam as necessidades para um novo currículo educacional, que será compilado dentro da Base Nacional Curricular Comum. Algumas das propostas buscam construir estratégias, organizadas em instrumentos padronizados, com o objetivo de suprir as necessidades específicas do discurso da eficácia da escola voltada para o mundo do trabalho. Grupos de educação privada como o Instituto Lehmann, Fundação Roberto Marinho, Instituto Natura,

Fundação Itaú Social, Instituto Singularidades são algumas das instituições que integram esse grupo. (Fonte: http://movimentopelabase.org.br/o-movimento/, Último acesso em 20 de fevereiro de 2017)
}

(C) ETD-Educação Temática Digital Campinas, SP v.19 $\quad$ n.1 $\quad$ p. 3-25 jan./mar. 2017 
estratégias dos cursos pré-vestibulares e de escolas particulares, enquanto que o que se deseja para a educação pública é um ensino cada vez mais voltado para a formação para o mercado de trabalho. Como nos afastar da ideia de um currículo como espetáculo? Ou como simples direcional de condutas dedicadas à classes sociais específicas? No fim (?) o que esses alunos nos interrogam é, exatamente, uma abertura para ouvir suas demandas, incorporar os múltiplos interesses na busca por oferecer conteúdos e currículo que desperte desejos e vontades. Uma escola que forme cidadãos críticos e criativos de maneira integral, e não apenas corpos estagnados que permanecem em tempo integral em uma escola que reproduz as desigualdades de oportunidades e falsas perspectivas. ${ }^{i}$

\section{REFERÊNCIAS}

AGAMBEN, Giorgio. Meios sem fim - notas sobre a política. Belo Horizonte: Autêntica, 2016.

BAZIN, André. Montagem proibida. In: O cinema - ensaios. Rio de Janeiro: Brasiliense, 1985.

BEY, Hakim. TAZ: zona autônoma temporária. São Paulo: Conrad, 2004.

BRASIL, André. Apresentação. In: DEVIRES - Cinema e Humanidades, v. 7, n. 2, 2010.

CAMPOS, Antônia M.; MEDEIROS, Jonas; RIBEIRO, Márcio M. Escolas de luta. São Paulo: Veneta, 2016.

FREIRE, Paulo. Escola pública e educação popular. In: Política e educação. São Paulo: Paz e Terra, 2014.

MIGLIORIN, Cezar. Inevitavelmente cinema - política, educação e mafuá. Rio de Janeiro: Azougue, 2015.

Igualdade dissensual: democracia e biopolítica no documentário contemporâneo.

In: Revista Cinética - Cultura e Pensamento, 2008.

PACHECO, José. Aprender em comunidade. São Paulo: SM, 2014.

RANCIÈRE, Jacques. A partilha do sensível: estética e política. São Paulo: Ed.34, 2012.

O desentendimento - política e filosofia. São Paulo: Ed. 34, 1996.

\footnotetext{
' Revisão gramatical do texto por: Cristina Praga

(C) ETD-Educação Temática Digital Campinas, SP v.19 n.1 $\quad$ p.3-25 jan./mar. 2017
} 